\title{
FORMULATION AND EVALUATION OF MICROSPHERES CONTAINING IMATINIB MESYLATE USING SODIUM ALGINATE BY CHEMICAL CROSS LINKING METHOD
}

\author{
*Senthil S Periasamy ${ }^{1}$, Nagesh R Sandu², Senthilkumar K Loganathan ${ }^{2}$ \\ ${ }^{1}$ The Erode College of Pharmacy and Research, Veppampalayam, Erode, Tamilnadu, India. \\ ${ }^{2}$ Padmavathi College of Pharmacy, Dharmapuri, Tamilnadu, India \\ *Corresponding Author’s E-Mail: senthilumasenthil@yahoo.co.in, Phone: +91 - 9443303975
}

Received 31 Sep 2012; Review Completed 05 Nov 2012; Accepted 09 Nov 2012, Available online 15 Nov 2012

\begin{abstract}
:
The present research deals with formulation of microspheres containing an Anti-cancer drug Imatinib mesylate reduce the side effects and frequency of dosing. It is currently registered and used for two indications, Chronic Myeloid Leukemia (CML) and Gastrointestinal Stromal Tumors (GISTs). Imatinib mesylate loaded microspheres was formulated by using Sodium Alginate polymer by Chemical CrossLinking method to develop a sustained release dosage form. The effect of concentration of polymer ratio on the microspheres properties like percentage of drug loading, biodegradability, drug release kinetics, particle size, encapsulation efficiency, angle of repose, bulk density, SEM, DSC and XRD were investigated in our study. Moreover, the kinetics of Imatinib Meyslate released from different formulations of microspheres were analyzed using four different theoretical models, that is Zero order, First order, Peppa's and Higuchi models. Microspheres prepared with Glutaraldehyde showed different release kinetics. Increasing the polymer concentration decreased the release rate of Imatinib Meyslate from microspheres because of formation of greater structural strength and more tightly texture with the drug. Besides, microspheres gave an adequate fit to either zero order or first order kinetic models, depending on the extent of cross linking reaction between drug and the cross linking agent.

Key Words: Sodium Alginate, Imatinib Mesylate, microsphere, chemical cross linking, release kinetics.
\end{abstract}

\section{INTRODUCTION}

Microspheres are defined as homogenous, monolithic particles in the size range of about $1.0-1000 \mu \mathrm{m}$ and are widely used as drug carriers for Sustained release. Administration of the drug in the form of microspheres usually improves the action by providing the localization of the active substance at the site of action and by sustaining the release of drugs. Glutaraldehyde was used as cross-linking agent to extent the release of the drug from the formulation. It may have more advantage to deliver this drug in a sustained release dosage form. The present study was focused on development of sustained release Imatinib mesylate using Chemical Cross linking method. Imatinib Mesylate is currently registered in adults for two indications: (a) monotherapy in Chronic Myeloid Leukemia (CML) and (b) Metastatic Gastrointestinal Stromal Tumors (GISTs).

\section{EXPERIMENTAL}

\section{Materials}

Imatinib Mesylate ${ }^{1,2}$ was procured as a gift sample from Natco Pharma Limited, Mumbai (India). Sodium Alginate $^{3-6}$ was obtained from Safe Pharma, Narasaraopet as gift sample. All chemicals were of analytical grade and were used without further purification.

\section{Method of preparation ${ }^{7-9}$}

A $4.0 \%$ (w/v) Polymer solution in aqueous acetic acid (5.0\%) was prepared. This dispersed phase was added to continuous phase $(100 \mathrm{~mL})$ consisting of light liquid paraffin and $25 \mathrm{ml}$ of Petroleum ether containing $2.0 \mathrm{ml}$ of Span 80 in a beaker at room temperature. Stirring was continued at $2000 \mathrm{rpm}$ using a 3 - blade half moon paddle for 5 minutes. A drop-by-drop solution of a measured quantity $(2.5 \mathrm{~mL}$ each) of aqueous glutaraldehyde $(25 \%$ $\mathrm{v} / \mathrm{v})$ saturated with toluene was added at 15,30, 45, and 60 minutes. Stirring was continued for 2.0 hours and separated by centrifugation and washed, first with petroleum ether $\left(60^{\circ} \mathrm{C}-80^{\circ} \mathrm{C}\right)$ four times, once with acetone and then thrice with distilled water to remove the adhered liquid paraffin and glutaraldehyde, respectively. The microspheres were then finally dried at room temperature and stored in vacuum desiccators.

\section{Compatibility studies ${ }^{10,11}$}

One of the requirements for the selection of suitable carrier for pharmaceutical formulation was compatibility. Therefore in the present work a study was carried out by using FTIR spectrophotometer to find out if there are any possible chemical interactions between Imatinib mesylate, sodium Alginate.

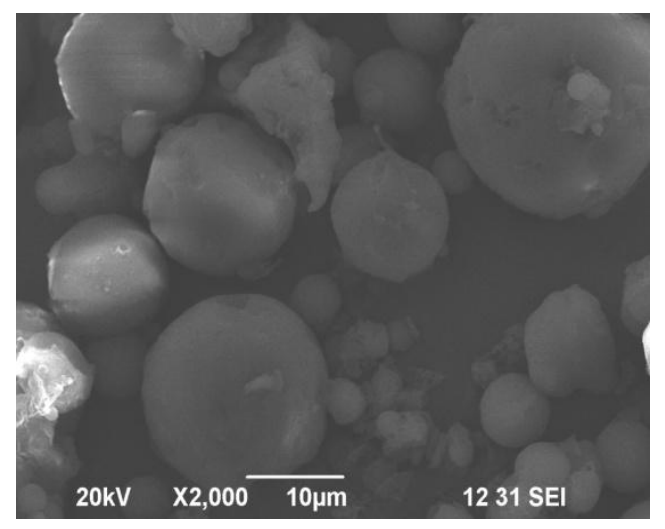

Figure 1: FCC3 Optimised formulation 


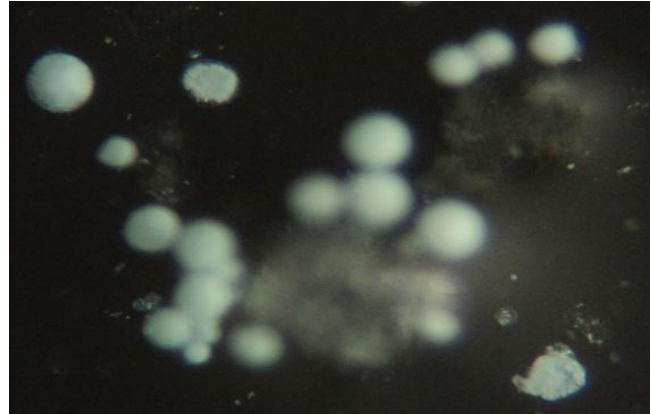

Figure 2: FCC3 Optical microscopic photo

\section{Particle size analysis ${ }^{12-14}$}

The microsphere size distribution was determined by the optical microscopy method using a calibrated stage micrometer $(\mu \mathrm{m})$.

\section{Angle of repose}

The fractional force in the loose powder can be measured by the angle of repose. Angle of repose was calculated by static method using fixed funnel method. This was the maximum angle possible between the surfaces of the site of the powder to the horizontal plane.

\section{Determination of bulk density}

The bulk density was determined by 3-tap method. Bulk density is defined as, "the mass of powder divided by the bulk volume". The packing characteristics of the powder play an important role in determining physical properties of product.

Table 1: Micromeritic Evaluation of Microspheres

\begin{tabular}{|c|c|c|c|c|c|c|}
\hline $\begin{array}{c}\text { Formulation } \\
\text { Code }\end{array}$ & Particle size & Angle of Repose & Bulk Density & Tapped Density & $\begin{array}{c}\text { Carr's Index } \\
\text { Hausner's } \\
\text { Ratio }\end{array}$ \\
\hline FCC1 & $100.45 \pm 1.906$ & $21.59 \pm 1.073$ & $0.845 \pm 0.010$ & $0.965 \pm 0.012$ & $12.40 \pm 0.928$ & $1.27 \pm 0.240$ \\
\hline FCC2 & $102.88 \pm 3.042$ & $21.59 \pm 1.532$ & $0.850 \pm 0.002$ & $0.970 \pm 0.021$ & $12.34 \pm 2.068$ & $1.14 \pm 0.027$ \\
\hline FCC3 & $105.08 \pm 1.981$ & $23.11 \pm 0.587$ & $0.846 \pm 0.016$ & $0.970 \pm 0.028$ & $12.64 \pm 4.117$ & $1.15 \pm 0.052$ \\
\hline FCC4 & $104.28 \pm 1.825$ & $23.01 \pm 0.907$ & $0.853 \pm 0.008$ & $0.969 \pm 0.023$ & $9.82 \pm 1.376$ & $1.11 \pm 0.016$ \\
\hline FCC5 & $107.62 \pm 2.385$ & $23.15 \pm 0.530$ & $0.831 \pm 0.020$ & $0.955 \pm 0.014$ & $12.91 \pm 3.443$ & $1.14 \pm 0.044$ \\
\hline
\end{tabular}

\section{Determination of drug content}

Accurately weighed microspheres equivalent to $25 \mathrm{mg}$ of Imatinib mesylate, crushed in glass mortar and pestle and the powdered microspheres were suspended in $100 \mathrm{~mL}$ of $0.1 \mathrm{~N} \mathrm{HCl}$. After 24 hours, the solution was filtered and the filtrate was analyzed for the drug content.

\section{Encapsulation efficiency $^{15}$}

Encapsulation efficiency was calculated using the following formula;

$$
\text { Encapsulation Efficiency } \frac{\text { Estimated Drug Content } \%}{\text { Theoretical Drug Content } \%} \times 100
$$

\section{In- vitro dissolution studies ${ }^{16}$,}

The drug release study was performed using USP XXIII dissolution test apparatus, the capsules filled with equivalent amount of Imatinib Meyslate $100 \mathrm{mg}$ was placed in a basket. The instrument was set at 100 - rpm rotation and at $32^{\circ} \mathrm{C}, 900 \mathrm{~mL}$ of $0.1 \mathrm{~N} \mathrm{HCl}$ was filled as dissolution medium for first 2 hours and phosphate buffer $\mathrm{pH} 7.4$ for remaining period. Samples were withdrawn at predetermined intervals, from $0.5-24$ hours filtered and analyzed spectrophotometrically at $230 \mathrm{~nm}$ using corresponding medium as blank. After each withdrawal, the same quantity of fresh medium was replaced immediately.

\section{Kinetic characteristics of the drug release ${ }^{17-19}$}

To know the mechanism of the drug release from the microspheres, the results obtained from the In-vitro dissolution process were fitted into different kinetic equations as follows:
1. Zero - order drug release: Cumulative $\%$ drug release Vs Time.

2. First order drug release: Log cumulative $\%$ drug retained Vs Time.

3. Higuchi's classical diffusion equation: Cumulative \% drug release Vs Square root of time.

4. Peppa's Korsemeyer Exponential equation: Cumulative $\%$ drug release Vs Log time.

' $n$ ' values can be used to characterize diffusion release mechanism.

\section{Stability studies ${ }^{20}$}

The Optimised preparation was divided into 3 sets and was stored at $4{ }^{\circ} \mathrm{C}$ (refrigerator), room temperature and $40^{\circ} \mathrm{C}$ (thermostatic oven). After 15, 30, 60, 90 drug content and SEM of the formulation was determined.

\section{RESULTS AND DISCUSSION}

We formulated 5 formulations using sodium alginate with different ratios. The characterisation of formulations were studied in particle size, angle of repose, bulk density, tapped density, percentage yield, drug content, Hausner's ratio, carr's index and cumulative percentage of drug release. The sustained release microspheres of all batches were found to be spherical and free flowing nature based on the SEM analysis. FTIR studies said that there were no incompatability between drug and polymer. Formulated microsphere particle size showed the range from 107.62 (FCC5) - 100.45 (FCC1). The angle of repose for the formulated microspheres found to be within the range 23.15-21.59 and showed moderate to good flow in nature. The formulation shows the bulk density values are from 0.970-0.955 indicating moderate flow characterstics of 
microspheres. The percentage yield of the formulations were 81.35 (FCC1) - 86.42 (FCC3). The drug content was started from 22.18 (FCC3) to 19.61 (FCC1). The drug encapsulation efficiency was found to be $789.05-87.12$ and said that drug polymer blend was good to made microspheres. Stability studies stated that ther was not much difference in the drug content and slight difference in the SEM analysis. The In-vitro drug release for all formulation was found to follw Non- Fickian diffusion release kinetics.

Table 2: Evaluation of Microspheres

\begin{tabular}{|c|c|c|c|c|c|c|}
\hline $\begin{array}{c}\text { Formulation } \\
\text { Code }\end{array}$ & \% yield & $\begin{array}{c}\text { Encapsulation } \\
\text { Efficiency }\end{array}$ & Drug Content & In-vitro Release & 'n'Value & $\mathrm{R}^{2}$ Value \\
\hline FCC1 & $81.35 \pm 0.579$ & $79.05 \pm 0.540$ & $19.61 \pm 0.374$ & $99.01 \pm 0.273$ & 0.637 & 0.993 \\
\hline FCC2 & $84.05 \pm 0.912$ & $83.71 \pm 0.665$ & $20.85 \pm 0.692$ & $99.38 \pm 0.209$ & 0.615 & 0.996 \\
\hline FCC3 & $86.42 \pm 0.290$ & $87.12 \pm 1.378$ & $22.18 \pm 0.470$ & $99.60 \pm 0.238$ & 0.615 & 0.992 \\
\hline FCC4 & $83.70 \pm 0.461$ & $79.47 \pm 0.506$ & $21.73 \pm 1.070$ & $97.64 \pm 0.422$ & 0.540 & 0.944 \\
\hline FCC5 & $84.33 \pm 0.494$ & $81.37 \pm 0.865$ & $20.21 \pm 0.420$ & $98.65 \pm 0.349$ & 0.630 & 0.995 \\
\hline
\end{tabular}

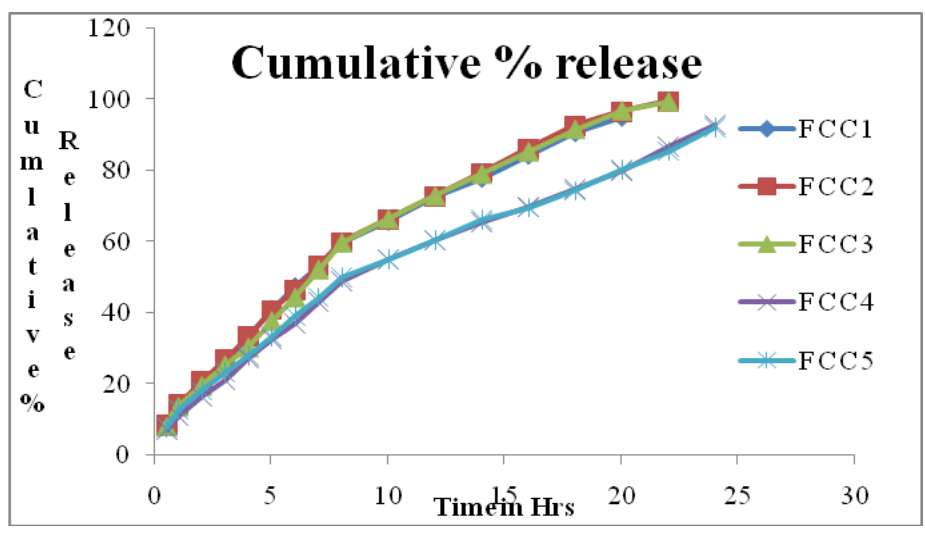

Figure 1: Cumulative \% release of Microspheres

\section{CONCLUSION}

From our study, it was concluded that the Imatinib Mesylate ( $\alpha$-form) loaded microspheres prepared by crosslinking agent Glutaraldehyde with Sodium Alginate with different ratios showed decreased in the release rate of drug from the formulation depending on the concentration of the polymers. The concentration of the polymers influenced the drug release pattern and polymer impregmentation depending upon cross-linking agent. The formulation with drug and polymers in 1:3 ratio (FCC3) with cross linking agent maximum concentration was considered best because, it showed retard drug release in $\mathrm{pH} 7.4$ buffer was found to be $99.60 \%$ almost complete and uniform after the 24hour release study. Drug encapsulation efficiency for formulation (FCC3) was

\section{REFERENCE:}

1. Indian Pharmacopoeia. Ministry of Health \& Family welfare, Govt. of India, Indian Pharmacopoeia Commission, New Delhi. 2010, Vol II, P 1484 - 1485

2. R Karthikeyan, B Thangabalan, A Elphine Prabahar and $\mathbf{P}$ Vijayaraj Kumar. New Spectrophotometric Methods for the Determination of Imatinib in Bulk Drug and in Pharmaceutical Formulations. Research Journal Pharmacy and Technology. 2009, 2(3), $578-581$.

3. Kim C. K., Lee E. J. The controlled release of blue dextran from alginate beads. International Journal of Pharmaceutics. 1992, 79(13), 11 - 19

4. Bhagat H. R., Mendes R. W., Mathiowitz E., Bhargava H. N. Chitosan-Alginate Microparticles as a Protein Carrier. Drug Development and Industrial Pharmacy.2001, 27(5) , 393-400
$87.12 \% \mathrm{w} / \mathrm{w}$ and all the remaining parameters were within the prescribed limit. Stability studies showed that the optimised formulation not much altered the drug content and SEM report. Optimised formulations toxicological study was done and observed data were showed that no significance of toxicological difference. As per the results concluded hte formulation FCC3 fully satisfy in all expectation.

\section{ACKNOWLEDGMENTS}

The authors also gratefully acknowledge to Principal and management, The Erode College of Pharmacy, Erode, for giving us the necessary facilities and support for carrying out the research work. 
9. Garg Tarun, Murthy RSR, Patented Microencapsulation Techniques and Its Application, Journal of Pharmacy Research, 2011, 4(7), 2097-2102.

10. Skoog, Holler," Principles of Instrumental Analysis" $5^{\text {th }}$ Edition, 2007, P 380-426

11. John. R. Dyer. Applications of Absorption Spectroscopy of Organic Compounds by Indian Edition, 2005, P 33-38.

12. Alferd Martin, Pillar Bustamante, A H E Chun, Micromeritics, in "Physical Pharmacy", Lippincott Williams \& Wilkins, $4^{\text {th }}$ Edition, 2001, P 427-429.

13. V S Subramanyam, "Physical Pharmaceutics", $2^{\text {nd }}$ Edition, Vallabh Prakashan - Delhi; 2000, P 180-210.

14. Leon Lachman, Herbert A Lieberman, Joseph L Kanig, Micromeritics and coating of capsule, in "Theory and Practice of Industrial Pharmacy", Lea \& Febiger, Philadelphia, $2^{\text {nd }}$ Edition, $\mathrm{P}$ 425-436

15. Yung-Kwan Chun, Hongkee Sah, Hoo-Kyun Choi. "Preparation of microspheres containing antimicrobial agents for eradication of $H$.
Pylori." International Journal of Pharmaceutics. 2005, 297, 172 179.

16. Paulo Costa, Jose Manuel Sousa Lobo. "Modeling and comparison of dissolution profiles". European Journal of Pharmaceutical Sciences. 2001, 13, 123-133.

17. Korsmeyer R. W., Gurny R. Peppas, "Mechanism of Solute Release From Porous Hydrophilic Polymers." International Journal of Pharmaceutics.1983, 15 (1), 25-35.

18. Higuchi T., "Mechanism of Sustained Action Medication: Theoretical Analysis of Rate of Release of Solid Drug Dispersed in Solid Matrix." Journal of Pharmaceutical Sciences, 1963, 52(12), 1145-1149.

19. Alfred Martin. Diffusion and Dissolution. In: "Physical Pharmaceutics", Lippincott Williams and Wilkins. Maryland. USA. $4^{\text {th }}$ Edition, 2001, P. $324-361$.

20. Harshad Parmar, Sunil Bakliwal, Nayan Gujarathi. Different methods of formulation and evaluation of mucoadhesive microsphere. International Journal of Applied Biology and Pharmaceutical Technology. 2010, 1(3), 1157-1167. 